\title{
Innovation in Education: Utilization and Employment of e-Books in Philippine Educational Institutions
}

\author{
Teresa Paula S. De Luna
}

\begin{abstract}
E-book technology is transforming the publishing industry and impacting education globally. In the Philippines, three varying utilization and employment strategies by early-adopting educational institutions are dramatized and examined as a rhetorical situation using Pentad analysis. Students are identified as the main audience in the rhetorical situation of e-books in education.
\end{abstract}

Index Terms-E-book, education technology, pentad analysis, Philippines, rhetorical situation.

\section{INTRODUCTION}

Education is vital in forming every community member's social self. In essence, society educates its members to "behave" in such a manner that it desires; hence, the institutionalization and formal implementation of education. Presently, the formal education institutionalized in Philippine society is highlighted as it takes on the challenge of the conservation of our culture in the midst of technological innovations impacting both local and global communities. As with the rest of the world, electronic book (e-book) technology has already started to make inroads into the Philippine educational system's teaching and learning processes. This paper focuses on how Filipinos are presently responding and planning future actions to this pressing matter in the management of education where both intellectual and economic considerations are put to fore.

\section{Theoretical Perspective}

Technology is one powerful trigger to culture change. This contention is the focus of Leslie White's explanation to how we social beings undergo the process of modifying our way of life. This theoretical lens discusses how technology will inevitably exact change in societies.

He states that culture is organized in such a manner through subdividing the whole cultural system into three subsystems, namely:

- Technological - composed of material mechanical, physical and chemical instruments;

- Sociological - made up of interpersonal relations expressed in individual and collective patterns of behavior, and;

- Ideological - composed of ideas, beliefs, knowledge expressed in articulate speech or other symbolic form.

The three subsystems are interconnected. According to

Manuscript received February 6, 2014; revised May 6, 2014.

Teresa Paula S. De Luna is with College of Arts and Letters, University of the Philippines, Philippines (e-mail: tpdlph@yahoo.com).
White [1], technology also dictates how the sociological and ideological subsystems are formed. As a result it has the potential to create or build a culture, but it also possesses the capability to destroy it. Will e-books impact discernible modifications in the "way" we experience learning? Are the consequences of the introduction and adoption of this new technology potent enough for the Philippine educational system to be prompted to change its current conduct of the economic and financial transactions, paradigms and pedagogies of learning?

\section{MethodologY}

The study is exploratory in nature, focusing on the presentation, discussion and examination of three models of adoption of e-book technology in three different educational institutions: a private high school, a private university and a department in the Philippines' national university. Specific aspects of e-book adoption examined are choices of devices and content, platform and delivery including use of EPUB file format and digital rights management (DRM), and pace of adoption.

In order to assess the connection and association of the socio-cultural elements involved in the phenomena of the adoption of e-book technology in educational institutions, I adopt Kenneth Burke's pentad analysis [2] wherein he identifies five elements of a rhetorical situation, examines each and its relation to other elements in order to elucidate and make sense of the occurrence of various phenomena, oftentimes social phenomena involving human behavior Burke's [2] analysis may be initially intended for rhetorical criticism, however, since rhetoric as a field has expanded, any communicative action may be regarded as a rhetorical situation. Covino [3] affirms this assertion in his expanded explication of the study of rhetoric. Covino [3] states that the field is the study of any text primarily verbal, situationally contingent, epistemic art that is both philosophical and practical and gives rise to potentially active texts. Text in this study is considered as the e-book technology phenomenon, which is within a rhetorical context - educational innovation. The context is examined as a rhetorical situation, which according Bitzer [3] is a situation where three social factors are present:

- Exigence - generative timeliness or a need for a text to be generated

- Audience - the people who have reason to be concerned about the situation

- Rhetorical constraints - features of the speaker's and the audience's frames of mind and belief systems.

The exigence in the e-book rhetorical situation is evinced 
by the growing popularity and number of e-book users. The existence and success of giant companies, such as Amazon, Apple and Kobo, which make money from commercial e-book technology, are proof that there is exigency in the text In this study, the audience is composed of educational institutions, students, educators and the business community. Rhetorical constraints are focused on reconciling traditional existing beliefs and practices with the arrival and introduction of e-book technology in the education sector directly traversing both economic and learning aspects.

Burke [2] on the other hand considers a rhetorical phenomenon as drama where elements are interrelated-one that provides an understanding of a rhetorical narrative with a sense of completeness and wholeness as each element is analyzed against another. He asserts the basic elements that affect human life are very similar to the components of the theater. According to Burke [2], dramatism is the key in making sense of people's actions and reactions. Human rhetorical transactions and interactions, just like the theater, can be better understood if we are able to identify, define, explain and analyze the five vital elements in the pentad: act, scene, agent, agency and purpose [4]. The pentad analysis [2] examines an element aligned with the existence of other elements.

\section{E-BOOKS IN EDUCATION}

There are three cases of the adoption of e-book technology presented in this paper: in a private high school, in a private university and in the national university.

\section{A. Private High School}

Miriam College High School is part of Miriam College [5] a non-stock, non-profit Filipino Catholic educational institution exclusively for females located in Quezon City, Philippines.

1) Device

Android tablet purchased by school for students.

2) Content

E-book versions of existing print textbooks in use for four subjects. Purchased by school from publishers.

3) Platform / delivery

Multi-platform consisting of different e-book reader applications, DRM systems, and content delivery mechanisms.

Two of the four publishers used a common local service provider to adopt EPUB format with Adobe DRM. E-books are delivered to students by having them download the DRM licenses and secured e-book files from publishers' websites prepared by the service provider. Authentication is through the use of access codes provided to the students and their identification details (name, school, grade level and email address).

One publisher used a proprietary e-book reader application and DRM system, with the e-book content delivered to students by copying the e-book files to the students' tablet devices from memory cards, also known as side-loading.

One publisher used a United States-based service provider to deliver a PDF e-book with proprietary DRM and in-app content delivery.

\section{4) Pace of adoption}

Started in School Year 2012-2013 with all First Year high school students and continues for all subsequent incoming First Year students.

\section{B. Private University}

Founded in 1934, Far Eastern University (FEU) [6] or Pamantasan ng Malayong Silangan is a private, non-sectarian educational institution.

\section{1) Device}

Students select and purchase their own tablet device with a choice between Apple Inc.'s iOS-based iPad or any Android tablet.

\section{2) Content}

Selected e-textbooks versions of printed textbooks previously in use for subject areas where the publisher is ready to deliver the e-textbook edition.

Purchased on behalf of students or allowed students to purchase from the same publishers of the previously used printed versions.

\section{3) Platform / delivery}

Used a local service provider to adopt EPUB file format with Adobe DRM and build a private e-bookstore integrated with the rest of the university's web portal. This allowed FEU to control and standardize the e-book technology platform and DRM settings on e-books from the different publishers. Publishers that provide educational content must use the system and sell through university's private e-bookstore.

E-book content is delivered to students by having them download the DRM licenses and secured e-book files from private e-bookstore site prepared by the service provider; students have the option of paying cash at the university for access codes to the e-books, or using online payment options on the private e-bookstore site.

\section{4) Pace of adoption}

Started in the second semester of school year 2013-2014 as a pilot program for select university courses and subject areas, with plan for wider implementation in school year 2014-2015 and to continue until all courses are covered and all materials are available in e-book format.

\section{National University}

The University of the Philippines (UP) [7] was established in 1908 and mandated by the Philippine government as the country's national university.

1) Device

Students select and purchase their own tablet device with a choice between Apple Inc.'s iOS-based iPad or any Android tablet.

\section{2) Content}

Required textbook for the subject Communication 3: Speech Communication under the Department of Speech and Theater Arts (DSCTA), College of Arts and letters, converted to EPUB format.

Entitled "Practical Speech Fundamentals" the e-book is authored by the DSCTA professors and published by the DSCTA itself through a service provider. 


\section{3) Platform / delivery}

Placed e-textbook on Flipreads [8], an online retailer of e-books in the Philippines and service provider to schools and textbook publishers.

E-book content is delivered to students by having them download it from Flipreads [8]. Students have the option of paying cash at the DSCTA office for access codes to the e-book, or using online payment options on Flipreads [8].

\section{4) Pace of adoption}

Started in the Second Semester of School Year 2012-2013 as an independent project of the DSCTA, covering all UP students taking up the Communications 3 subject in the main campus.

\section{DRAmatizing TeChNOlogy}

The ACT of e-book adoption is the main focus in the pentadic analysis. Other elements of the pentad are examined relative to ACT. The technological cultural system [9] as a primary initiator of culture change is demonstrated in this phenomenon that has permeated educational institutions. The introduction of the e-book technology to the Philippine society has effected changes in various sectors in the society, creating the need to modify already established processes of human conduct, where education is an aspect of utmost importance. To understand the progression of the initial process of culture change set-off by e-book technology, examination of the ACT in reference to the other pentad elements provides a comprehensive interpretive appreciation of the impact of a technological change in the Philippine cultural system, specifically of what may be considered as a dramatic pedagogical shift of learning - the act of reading books.

\section{A. The Scene to Act}

It was in 2012 when a number of educational institutions started to adapt to technological changes directly affecting our culture of the "act of reading". Prior to 2012, a small part of the Philippine population was already aware of the existence of the existence of e-books, but it was only during 2012 when schools located primarily in the National Capital Region took steps toward realigning educational and learning management to incorporate e-books in their systems. The SCENE here is the awareness of the educational community that a technological innovation has transpired that will inevitably affect and modify the process of learning. Typically, most communities (education community being one of the oldest and most traditional) with established traditions of "doing things" are diffident in embracing new processes, however other pressing circumstances in the society may prod community members to minimize cautiousness. The current constant flood of new technologies in the society creates a context where various ways of adaptations of people from different social categories are presented. For instance, the younger generation have already formed conducts and behaviors when they are consuming contents on the Internet, including YouTube videos, podcasts social media, blogs, etc. Gamers on the other hand have developed habits in handling and controlling their consoles or devices, while interacting with other gamers online. Markedly, these technological adaptations are mostly considered to be entertainment-related. However, it should be emphasized that the same faculties are utilized in all human interactions, including learning. The transformation of the physical appearance of books and consequently the act of reading books are part of the SCENE. Before the educational institutions' adaptation of e-book technology the SCENE has already been set for the ACT. The scene represents a dilemma in the academic community where most practitioners adhere to" theory into practice" pedagogy. It now presents a pedagogical shift to "practice into theory" when students are better experienced with new technologies compared to their teachers because they consume and are more comfortable in utilizing new technologies. According to some Filipino teachers [10], they are the ones who need to "migrate" to the "high-tech world" where the students seem to be the "natives."

\section{B. Agency to Act}

With the onset of the adaptation to e-books in schools, three models of adoption are presented and examined. The three cases of e-book technology adoption characterize the educational institutions' envisioned identity. The schools' models of employment represent their AGENCIES.

In the case of the private high school, the school administrators decided to adopt an almost a total paperless textbook platform. According to school officials, they want to make sure that they are updated and modernized at all times in adherence to their school's projected image, particularly on the part of offering ".... a college-preparatory program that features the interaction of the STEM (Science, Technology, Engineering, and Mathematics) fields, arts, and humanities, social sciences, and business and trades" [5]. At present, they are strengthening their programs in science and technology within the context of the global community. By changing the practice of reading from the printed textbook to e-book textbook, pragmatically they are also starting to transform and modernize an aspect of learning. In its initial phase, there are challenges that school educators and administrators encounter. For instance, teachers are still adjusting to a style of teaching where electronic gadgets are integrated to the process of teaching and learning as well as sudden technical glitches on the wireless Internet connection. Interestingly, the students appear to have experienced the modification with less difficulty compared to their teachers. The school recognizes the difficulties; however they want to emphasize that they want to be one of the pioneers of the employment of technological changes in their educational institution.

The private university on the other hand adopted a customized e-bookstore structure that was integrated into their overall website and student portal. Students could easily purchase and download text and reference e-books specifically required by professors. The university, however, does not as yet require its students to purchase only e-books. They recognize that the status quo is currently transitory. To ease the technological transformation, an almost complete eradication of printed books is not yet entertained. Along with how it defines itself as it "...nurtures a service-oriented and environment-conscious community, which seeks to contribute to the advancement of the global society", it aspires to be globally competitive in providing its students an 
educational environment that acknowledges and make use of technological innovations [6].

The third case shows a state university department that adapted to the e-book technology by converting their own content, which existed as a traditional printed book, into an e-book. The textbook is written by two professors in the department and specifically for the consumption of students enrolled in the university. It is observed that students would buy both the printed and electronic versions. This act may suggest a manner or form of adjustment of the acts of reading and learning. Students are not required to utilize a specific book format; however, they are seen to take advantage of the convenience of having an e-book copy on their cellphones or tablets whenever they forget to bring their printed books. The adoption of the department of the e-book technology is in line with the list of mandates the only national university of the Philippines is supposed to uphold, specifically the first mandate: "Lead in setting academic standards and initiating innovations in teaching, research, and faculty development in philosophy, the arts and humanities, the social sciences, engineering, natural sciences, mathematics, and technology; and maintain centers of excellence in these disciplines and professions" [7].

E-book technology certainly falls not only within the area of technological innovation directly linked to teaching and learning but also under researches that engage theoretical framings concerning the impact and consequence of human beings' adoption of and adaptation to "new" communication technologies.

\section{Actors to Act}

When educational institutions in the Philippines started to make use of the e-book technology, key ACTORS are inevitably affected. The students are one of the primary participants in the ACT. They are the main consumers of the new technology. According to preliminary accounts from all ACTORS the students appear to be the ones most comfortable with the usage of a new technology within the traditional context of the field of education. This should not be surprising since they are still in the process of construction; as students their skills and proficiencies are currently being formed and developed. They are also easily adaptable to "new things" compared to the other older ACTORS in the drama, including school administrators, teachers and traditional content providers or publishers.

The older actors themselves admit that the modification of the act of reading is a challenge having been educated and trained reading books in the printed form. Educators encounter pedagogical issues especially since they are themselves students in learning how to use a different and new tool for teaching. They note that easy and fast access to knowledge and data is an advantage of electronic learning. External links maybe included in e-books where users can immediately obtain additional information. Administrators confront challenges in dealing with parents of students, who are currently skeptical and unfamiliar with the change [10]. Almost all education managers find it difficult to select the most appropriate platform to employ for the specific culture and needs of their institutions. At present they acknowledge that they are still fine-tuning their systems in both the acquisition of e-books and electronic gadgets from providers and the distribution to their students. The common issue brought out by institutions is focused on their need for stronger technical Internet connection [5]-[7].

Changes have also transpired in the industries that service the education sector. The traditional service providers on the other hand were initially uncertain in their reaction to the emergence of the new technology. Publishers were initially threatened by the entry of e-books in the market given the presumption that it will destabilize their position in the industry. However, the technological innovation that has already gained access to the consciousness of consumers-including the education sector-eventually compelled the publishing industry to convert printed books to electronic data and publish in the e-book format. Some developed their own systems, others chose to partner with e-book service providers that use international standards for file formats, DRM and account-based delivery.

Market competition among manufacturers and distributors of electronic gadgets is robust, benefiting consumers with the availability of state-of-the-art and cutting-edge devices utilized in learning on continually cheaper prices. Indeed, e-book technology stimulated transformations not only on a single ACTOR's context; it has prompted interconnected changes amongst the other ACTORS that are shaping the current description of the state of education management with the adoption of e-books in the Philippines.

\section{Purpose to Act}

Technological innovations occur and when they do they transform the ways of life of communities fundamentally to surface an "improved" and "better-quality" of existence. Admittedly, such terms as "improved" and "quality" are culturally specific and relative. However, they generally present a context wherein people who employ these innovations are benefitted in one way or another. E-book technology aims to trigger modifications in the field of education by upgrading the learning tools alongside the inevitable fast-paced technological innovations in other sectors of the society. It also prompted learning institutions to modify their educational management systems [5]-[7]. In the course of this development the processes of learning and teaching are implicated, which brings about paradigmatic, pedagogical and pragmatic issues on how we view ourselves within a "changing world" generated by a technological change.

\section{CONCLUSION}

The exigency of continuous innovation in the field of education is always present. It reflects the importance of keeping relevant our pedagogies vis-à-vis social, cultural and economic realities. Given the education context, our students are the main audience in this rhetorical situation. They are the principal recipients of these transformations. In turn they will consequently generate new bodies of knowledge or shifts in paradigms depending on the experiences they will encounter. Since the education sector is not an independent entity, its support systems have to undergo changes as well, altering the way we understand education management. 


\section{REFERENCES}

[1] M. Henrietta and S. Todd, Anthropology in Theory Issues in Epistemology, Australia: Blackwell Publishing, 2006.

[2] K. Burke, Grammar of Motives, Berkeley, CA: University of California Press, 1945.

[3] W. A. Covino and D. A. Jolieffe, Rhetoric. Concepts, Definitions, Boundaries, Massachusetts: Allyn and Bacon, 1995.

[4] D. Luna and T. Paula, "E-SEA- Exploring the Impact of Electronic Publishing in Southeast Asia," presented at the 2011vICONSEA International Conference on Southeast Asia, Malaysia, December 6-7, 2011.

[5] Miriam College High School. [Online]. Avaiable: https://www.mc.edu.ph

[6] Far Eastern University of the Philippines. [Online]. Avaiable: http://www.feu.edu.ph

[7] University of the Philippines. [Online]. Avaiable: http://www.up.edu.ph.

[8] Flipreads. [Online]. Avaiable: http://www.flipreads.com

[9] L. White, "The Concept of Cultural Systems: A Key to Understanding Tribes and Nations," American Journal of Sociology, vol. 84, no. 4, pp. 1018-1021, Jan. 1979.
[10] Interview with Ms. Reina Rama, Assistant Principal for Academic Affairs Miriam College High School.

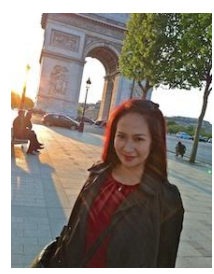

Teresa Paula S. De Luna is an assistant professor with the Department of Speech Communication and Theater Arts, College of Arts and Letters, University of the Philippines (UP) in Diliman, Quezon City. She received her undergraduate degree in speech and drama cum laude, as well as master's degree in speech communication from the same department, college and university. Prof. De Luna is currently working on her dissertation as a Ph.D. candidate in anthropology with the College of Social Science and Philosophy, also in UP.

In 19 years as a UP faculty member, she served as the managing director of Dulaang UP, the university's official theater company and in various college committees. At present, she is the coordinator of the Office of Anti-Sexual Harassment in UP-Diliman. Her research output and continuing interest are focused on the impact of technology on culture and society. 